\title{
2,2'-bipyrimidine as a Building Block for the Design of Emissive Conjugated Polymers for Hybrid LED Lighting
}

Qiqiao Lin, ${ }^{a}$ Xiaoguang Huang, ${ }^{a}$ Sasikumar Ramachandran, ${ }^{a}$ Xinyang Wang, ${ }^{a}$ Rachod Boonsin, ${ }^{b}$ Yasmine Khendriche, ${ }^{b}$ Rodolphe Valleix, ${ }^{b}$ Jean-Philippe Roblin, ${ }^{b}$ Damien Boyer, ${ }^{b}$ Geneviève Chadeyron, ${ }^{b}$ Gaël Zucchi*a

a. Laboratoire de Physique des Interfaces et des Couches Minces, LPICM, CNRS, Ecole polytechnique, IP Paris, 91128 Palaiseau, France.

b. Université Clermont Auvergne, CNRS, SIGMA Clermont, ICCF, F-63000 ClermontFerrand, France.

Corresponding author: gael.zucchi@polytechnique.edu

KEYWORDS: 2,2'-bipyrimidine, conjugated polymers, hybrid phosphor, photostability, LED lighting

\section{ABSTRACT}

This work introduces 2,2'-bipyrimidine as an acceptor unit in the design of donor-acceptor conjugated polymers. Regularly alternating this moiety with the electron-rich 2,7-dihexyl fluorene and 3,6-carbazole units lead to polymers P1 and P2, respectively, which both showed a red-shifted emission with respect to the parent polyfluorene and polycarbazole derivatives. Investigations on the thermal properties showed that P1 and P2 both possess decomposition temperatures higher than $250{ }^{\circ} \mathrm{C}$ under a mixture of $\mathrm{N}_{2}$ and $\mathrm{O}_{2} . \mathbf{P} 1$ was used as a representative example of this family of conjugated polymers to design white-emitting materials, both in solution and in the solid state. P1 and P2 were investigated as phosphors for 
LED lighting. Two composite films elaborated with P1 and P2 embedded into a PMMA matrix labelled P1c and P2c, respectively, were irradiated with a $375 \mathrm{~nm}-\mathrm{LED}$ at a power as high as $48 \mathrm{~W} / \mathrm{m}^{2}$. P1c was found to show a lower photostability. Two ways to improve the stability under UV exposure were investigated. On the one hand, replacing 2,7-dihexyl fluorene by 3,6-hexyl carbazole approximately improved the photostability by a factor of 2 , while, on the other hand, embedding the polymers into a liquid sol-gel hybrid matrix allowed an improvement of the stability by a factor of 3 . We could obtain a stabilization of the intensity of P2c at ca. half of its initial intensity, thus showing an improvement of the photostability of more than five times with respect to pure $\mathbf{P 1}$.

\section{INTRODUCTION}

Conjugated polymers show peculiar optoelectronic properties which have made them widely studied as active materials for various applications in the fields of optics and electronics. In the last three decades, the most investigated applications have been photovoltaic and electroluminescent devices, as well as field-effect transistors. Conjugated polymers were found to be highly interesting in the design of optical sensors as they show signal amplification, an effect first described by the Swager group in 1995. Efficient optical biosensors and chemical sensors using conjugated polymers as active materials have since been developed. ${ }^{1}$ More recently, new areas of interest have emerged, like thermoelectricity, ${ }^{2}$ imaging $^{3,4}$ or photodynamic therapy ${ }^{5-7}$, thus enlarging the fields of investigations of these materials. Research on conjugated polymers for opto-electronics has mainly focused on both the modification of the bandgap for increasing the absorption, and the improvement of the mobility of charge carriers. The way that has been the most used to lower the bandgap of conjugated polymers, and consequently improve their absorption of solar light, was to design (D-A)n polymers, a concept introduced in $1992 .{ }^{8}$ The regular alternation between electron- 
poor and electron-rich units within the backbone creates internal charge transfers that shorten the bond length between two consecutive units of different electron affinity, thus leading to a planarization of the backbone, and, consequently, to a better conjugation along the backbone, thanks to a favorized orbital overlap along the conjugated system. This results in a decrease in the value of the bandgap.

Lighting systems based on LEDs as source of light have recently become the most popular ones as they consume a low amount of electrical energy. They usually combine either a nearUV or a blue-emitting LED chip and several phosphor materials that convert the LED light into white light. For instance, white LEDs that are nowadays commercialized are made of a blue LED covered with a yellow phosphor in most cases associated with a red-emitting phosphor like $\mathrm{Eu}^{2+}$-doped sulfide or nitride to obtain warm-white emission, that partially converts the blue light into white light. ${ }^{9}$ The universal yellow phosphor is the inorganic YAG:Ce material of formula $\mathrm{Y}_{3} \mathrm{Al}_{5} \mathrm{O}_{12}: \mathrm{Ce}^{3+}$. It uses relatively high quantities of metals including Rare Earths, in addition of requiring high temperature synthesis. These represent serious drawbacks as resources of Rare Earths are limited, their exploitation has a negative impact on the environment, and the synthesis of such phosphors at high tonnages is highly energetic. However, the Rare Earths industry continues to be an important part of not only the development and manufacture of high-end technologies, but also as a geopolitical tool in an increasingly unstable and unpredictable global market. Disruptions to supply chains caused by fares, the imposition of sourcing restrictions for some products and uncertainty over the future of major producers has resulted in a renewed focus on either diversifying the source of Rare Earths products, particularly outside China, or limiting and decreasing the quantity of these metals. It is thus of importance to find innovative phosphors without or with lower Rare Earths loadings and with tunable emission that can be obtained by relatively cheap and lowenergy procedures and from abundant elements. 
Among emissive compounds, fluorescent organic conjugated polymers are of particular interest as they strongly emit in the visible range after absorbing near-UV to blue light with high absorption efficiencies. Also, grafting lateral chains increases their solubility in organic solvents, making them easily processable from solution deposition techniques. This is an asset as resulting devices can be fabricated at lower prices and various substrate materials can be used, broadening the areas of applications. Especially, polyfluorene derivatives have attracted a great deal of attention thanks to both their high emission efficiency in the visible, in particular in the blue, and their semiconducting properties. Thus, they have been widely investigated as blue emitters or matrices in electroluminescent devices. ${ }^{10-19}$ Comparatively, conjugated polymers have only very rarely been investigated as phosphors for LED lighting. ${ }^{20-27}$ Especially, the literature dealing with investigations on the photostability of such phosphors is almost virgin.

(D-A) $)_{\mathrm{n}}$ copolymers have led to excellent performance in optoelectronic devices. However, the number of acceptor units that was used in the last thirty years is still relatively limited. Within these lines, 2,2'-bipyrimidine appeared as an interesting candidate as the presence of two nitrogen atoms in the pyrimidine rings increase the electron affinity. If this molecule has been widely studied for designing coordination complexes, and especially with lanthanide ions $^{28-31}$ thanks to its bis-chelating properties, it has been very scarcely used to design more sophisticated organic molecules. ${ }^{32}$

We present in this paper that the introduction of the electron-deficient 2,2'-bipyrimidine core into the backbone of the blue-emitting poly(9,9- dihexyl-2,7-fluorene) (P1) and poly(9hexyl-3,6-carbazole) (P2) in an alternative way afforded (D-A)n copolymers with a redshifted emission with respect to that of the homopolymer. The thermal and photophysical properties of these two polymers have been investigated as well as their optical properties after excitation by a commercial UV LED. The behavior of their optical properties in solution 
is discussed. Composite films with P1 and P2 have been prepared and their photostability upon photonic stress have been investigated.

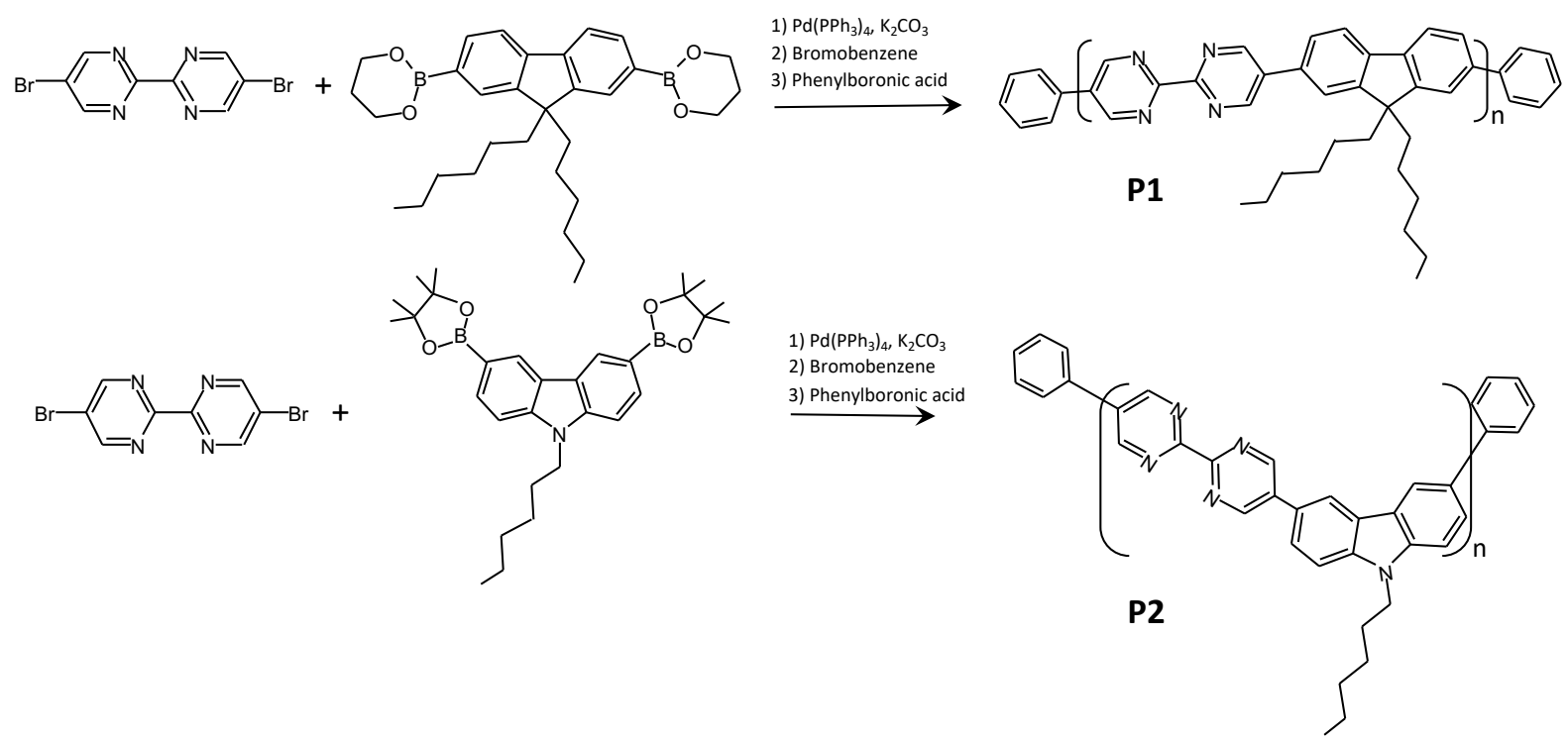

Scheme 1. Synthesis of $\mathbf{P 1}$ and $\mathbf{P 2}$.

\section{EXPERIMENTAL SECTION}

2.1. Materials. 2-chloropyrimidine, zinc, nickel chloride $\left(\mathrm{NiCl}_{2}\right)$, triphenylphosphine $\left(\mathrm{PPh}_{3}\right)$, bromine, bromobenzene and phenylboronic acid were purchased from VWR and used as received. 9,9-dihexyl-2,7-dibromofluorene, and 2,2'-(9,9-dihexyl-9H-fluorene-2,7diyl)bis(1,3,2-dioxaborinane) were purchased from Aldrich.

2.2. Synthesis. 2,7-dibromo-9-hexyl-9H-carbazole, ${ }^{15}$ and 9-hexyl-3,6-bis(4,4,5,5tetramethyl-1,3,2-dioxaborolan-2-yl)-9H-carbazole ${ }^{15}$ were prepared according to literature methods. Poly(9,9-di-n-hexyl-2,7-fluorene) (PF, Figure S1) $)^{16}$ and 9-(3(triethoxysilyl)propyl)carbazole $(\mathbf{C z - S i} \text {, Figure } \mathrm{S} 1)^{35}$ were synthesized from adapted procedures. All other chemicals and reagents were used as received from Aldrich, VWR and 
Alfa Aesar Chemical Co. unless otherwise specified. All solvents were carefully dried and purified before use. All manipulations involving air-sensitive reagents were performed under a dry argon atmosphere.

2,2'-bipyrimidine (C1). ${ }^{33}$ To a $100 \mathrm{~mL}$ dried round bottom flask charged with $\mathrm{PPh}_{3}(4.58 \mathrm{~g}$, $17.5 \mathrm{mmol}), \mathrm{NiCl}_{2}(0.57 \mathrm{~g}, 5.4 \mathrm{mmol})$ and $\mathrm{Zn}(0.57 \mathrm{~g}, 8.7 \mathrm{mmol})$, dry DMF (20 mL) was added under argon and stirred vigorously at room temperature for $1 \mathrm{~h}$. 2-chloropyrimidine $(2.00 \mathrm{~g}, 17.5 \mathrm{mmol})$ was added under argon. The solution slowly turned dark. After $1 \mathrm{~h}$, the temperature was increased to $80{ }^{\circ} \mathrm{C}$ for $70 \mathrm{~h}$. Then the reaction mixture was cooled to room temperature, filtered through celite, and concentrated under vacuum. The brown residue was washed with chloroform and DMF and an aqueous solution of EDTA-Na ${ }^{+}(7.27 \mathrm{~g}, 17.5$ mmol) was added to the residue. After stirring for $3 \mathrm{~h}$, the solution was washed with diethyl ether $(3 \times 50 \mathrm{~mL})$ and $\mathrm{CHCl}_{3}(8 \times 50 \mathrm{~mL}) \cdot \mathrm{CHCl}_{3}$ was removed under vacuum and the residue was recrystallized from diethyl ether/hexane to yield the product as a yellow solid (1.42 g, 51\% yield).

${ }^{1} \mathrm{H} \mathrm{NMR}\left(300 \mathrm{MHz}, \mathrm{CDCl}_{3}, \delta\right) 9.02(\mathrm{~d}, J=4.8 \mathrm{~Hz}, 4 \mathrm{H}), 7.44$ (t, $\left.J=4.8 \mathrm{~Hz}, 2 \mathrm{H}\right)$.

${ }^{13} \mathrm{C}$ NMR $\left(75 \mathrm{MHz}, \mathrm{CDCl}_{3}, \delta\right)$ 161.8, 157.6, 121.2.

HRMS (ESI-P/Q-TOF) m/z: [MH] ${ }^{+}$Calcd 159.0665 for $\mathrm{C}_{8} \mathrm{H}_{7} \mathrm{~N}_{4}$; Found 159.0666.

5,5'-dibromo-2,2'-bipyrimidine (M1). ${ }^{34}$ 2,2'-bipyrimidine (0.55 g, $\left.3.5 \mathrm{mmol}\right)$ and bromine $(1.43 \mathrm{~mL}, 27.8 \mathrm{mmol})$ were heated at $150^{\circ} \mathrm{C}$ under argon in a sealed tube for $72 \mathrm{~h}$. The mixture was cooled and the hard solid was powdered and treated with a solution of $\mathrm{Na}_{2} \mathrm{SO}_{3}$ to remove the unreacted bromine. The residue was washed with the minimum amount of THF, then extracted with $\mathrm{CHCl}_{3}$. The organic part was concentrated under vacuum and the residue was recrystallized from $\mathrm{CHCl}_{3} /$ hexane to yield the product as a yellow solid $(0.83 \mathrm{~g}, 76 \%$ yield).

${ }^{1} \mathrm{H}$ NMR $\left(300 \mathrm{MHz}, \mathrm{CDCl}_{3}, \delta\right) 9.05(\mathrm{~s}, 4 \mathrm{H})$.

${ }^{13} \mathrm{C}$ NMR (75 MHz, $\left.\mathrm{CDCl}_{3}, \delta\right)$ 159.7, 158.9, 121.9. 
3,6-dibromo-9-hexyl-9H-carbazole (M2). ${ }^{15}$ To a dried flask was added 3,6-dibromo-9Hcarbazole $(2.00 \mathrm{~g}, 6.15 \mathrm{mmol})$ and $20 \mathrm{~mL}$ of anhydrous THF under argon. Sodium hydride $(0.49 \mathrm{~g}, 12.30 \mathrm{mmol})$ was added into the flask at $0^{\circ} \mathrm{C}$ and stirred for $30 \mathrm{~min} .1$-bromohexane (1.74 $\mathrm{mL}, 18.50 \mathrm{mmol})$ was added dropwise and the mixture was refluxed for $12 \mathrm{~h}$. The reactant was cooled to room temperature and water was added. After extraction with ethyl acetate for three times, the organic part was dried under vacuum. The residue was purified by column chromatography (ethyl acetate:hexane $=1: 5)$ to yield a white crystalline product $(2.56$ g, 99\% yield).

${ }^{1} \mathrm{H}$ NMR (300 MHz, $\left.\mathrm{CDCl}_{3}, \delta\right) 8.14(\mathrm{~s}, 2 \mathrm{H}), 7.54(\mathrm{~d}, J=8.7 \mathrm{~Hz}, 2 \mathrm{H}), 7.26(\mathrm{~d}, J=8.7 \mathrm{~Hz}, 2 \mathrm{H})$, $4.23(\mathrm{t}, J=7.2 \mathrm{~Hz}, 2 \mathrm{H}), 1.82(\mathrm{t}, J=6.9 \mathrm{~Hz}, 2 \mathrm{H}), 1.30-1.20(\mathrm{~m}, 6 \mathrm{H}), 0.85(\mathrm{t}, J=6.0 \mathrm{~Hz}, 3 \mathrm{H})$.

${ }^{13} \mathrm{C}$ NMR (75 MHz, $\left.\mathrm{CDCl}_{3}, \delta\right)$ 139.3, 129.0, 123.4, 123,3, 111.9, 110.4, 43.4, 31.5, 28.8, 26.9, $22.5,14.0$.

HRMS (ESI-P/Q-TOF) m/z: [MH] ${ }^{+}$Calcd 407.9957 for $\mathrm{C}_{18} \mathrm{H}_{20} \mathrm{Br}_{2} \mathrm{~N}$; Found 407.9955.

9-hexyl-3,6-bis(4,4,5,5-tetramethyl-1,3,2-dioxaborolan-2-yl)-9H-carbazole (M3). ${ }^{15}$ То а solution of 3,6-dibromo-9-hexyl-9H-carbazole (1.00 g, $2.4 \mathrm{mmol})$ in THF (30 mL) in a dried flask at $-78{ }^{\circ} \mathrm{C}$ was added $\mathrm{n}-\mathrm{BuLi}(4.1 \mathrm{~mL}, 10.3 \mathrm{mmol})$ dropwise under argon. After stirring for $1 \mathrm{~h}$, 2-isopropoxy-4,4,5,5-tetramethyl-1,3,2-dioxaborolane (2.1 $\mathrm{mL}, 10.3 \mathrm{mmol})$ was rapidly added to the solution and the mixture was stirred at $-78^{\circ} \mathrm{C}$ for another $1 \mathrm{~h}$. Then the reactant medium was warmed to room temperature and stirred overnight. The mixture was poured into water and extracted with diethyl ether. The organic layer was dried over anhydrous $\mathrm{MgSO}_{4}$ and concentrated under vacuum. The residue was purified by column chromatography (ethyl acetate:hexane $=1: 5$ ) and recrystallized from $\mathrm{MeOH}$ and acetone (10:1). The product was obtained as a white solid ( $0.69 \mathrm{~g}, 56 \%$ yield). 
${ }^{1} \mathrm{H}$ NMR $\left(300 \mathrm{MHz}, \mathrm{CDCl}_{3}, \delta\right) 8.70(\mathrm{~s}, 2 \mathrm{H}), 7.92(\mathrm{~d}, J=8.1 \mathrm{~Hz}, 2 \mathrm{H}), 7.40(\mathrm{dd}, J=1.5 \mathrm{~Hz}, 8.1$ $\mathrm{Hz}, 2 \mathrm{H}), 4.30(\mathrm{t}, J=6.3 \mathrm{~Hz}, 2 \mathrm{H}), 1.90-1.80(\mathrm{~m}, 2 \mathrm{H}), 1.50-1.30(\mathrm{~m}, 30 \mathrm{H}), 0.86(\mathrm{t}, J=1.5 \mathrm{~Hz}$, $3 \mathrm{H})$.

${ }^{13} \mathrm{C}$ NMR $\left(75 \mathrm{MHz}, \mathrm{CDCl}_{3}, \delta\right)$ 142.7, 132.1, 128.1, 122.9, 108.2, 83.6, 43.1, 31.6, 28.9, 26.9, $25.0,24.9,22.6,14.1$.

HRMS (ESI-P/Q-TOF) m/z: [MH] ${ }^{+}$Calcd 504.3451 for $\mathrm{C}_{30} \mathrm{H}_{44} \mathrm{~B}_{2} \mathrm{NO}_{4}$; Found 504.3458.

9-(3-(triethoxysilyl)propyl)carbazole (Cz-Si). This was synthesized from an adaptation of the synthesis pathway reported. ${ }^{35}$ To a $200 \mathrm{~mL}$ flame dried round bottom flask charged with carbazole $(5 \mathrm{~g}, 0.030 \mathrm{~mol})$ and dry THF $(100 \mathrm{~mL})$ at $0{ }^{\circ} \mathrm{C}$ was added $\mathrm{NaH}(1.435 \mathrm{~g}, 0.036$ mol) under argon. (3-chloropropyl)triethoxysilane $(7.201 \mathrm{~g}, 0.030 \mathrm{~mol})$ was added to the mixture after $1 \mathrm{~h}$ and the reaction was stirred at $80{ }^{\circ} \mathrm{C}$ overnight. The mixture was filtered, concentrated in vacuum, and purified by flash column chromatography with petroleum ether/ethyl acetate $(\mathrm{v} / \mathrm{v}=15: 1)$ to afford a brown liquid product $(4.158 \mathrm{~g}, 37 \%$ yield).

${ }^{1} \mathrm{H}$ NMR (300 MHz, $\left.\mathrm{CDCl}_{3}, \delta\right) 8.13(\mathrm{~d}, J=7.8 \mathrm{~Hz}, 2 \mathrm{H}), 7.47-7.49$ (m, 4H), 7.22-7.28 (m, 2H), $4.34(\mathrm{t}, J=7.5 \mathrm{~Hz}, 2 \mathrm{H}), 3.79-3.86(\mathrm{~m}, 6 \mathrm{H}), 2.00-2.06(\mathrm{~m}, 2 \mathrm{H}), 1.23(\mathrm{t}, J=7.2 \mathrm{~Hz}, 9 \mathrm{H})$, $0.71-0.76(\mathrm{~m}, 2 \mathrm{H})$.

${ }^{13} \mathrm{C}$ NMR (75 MHz, $\left.\mathrm{CDCl}_{3}, \delta\right)$ 140.5, 125.6, 122.8, 120.3, 118.7, 108.8, 58.5, 45.3, 22.4, 18.3, 7.9.

HRMS (ESI-P/Q-TOF) m/z: [ MNa] Calcd 394.1809 for $\mathrm{C}_{21} \mathrm{H}_{29} \mathrm{NaNO}_{3} \mathrm{Si}$; Found 394.1809.

General procedure for polymers synthesis. P1, and P2 were obtained from SuzukiMiyaura coupling reactions following a revised procedure previously reported. ${ }^{14,15}$

Poly(2,2'-bipyrimidine-alt-2,7-(9,9-dihexyl-9H-fluorene)) (P1). 5,5'-dibromo-2,2'bipyrimidine (100 mg, $0.3 \mathrm{mmol}$ ) and 2,2'-(9,9-dihexyl-9H-fluorene-2,7-diyl) bis(1,3,2- 
dioxaborinane) (159 mg, $0.3 \mathrm{mmol})$ were added to a $25 \mathrm{~mL}$-flame-dried three-neck round bottom flask. $10 \mathrm{~mL}$ of DMF were added to dissolve the solid and then $\mathrm{K}_{2} \mathrm{CO}_{3}(131 \mathrm{mg}, 0.9$ mmol) was added. 5 min later, water $(2 \mathrm{~mL})$ was added and the reactant medium was degassed for $30 \mathrm{~min} . \mathrm{Pd}\left(\mathrm{PPh}_{3}\right)_{4}(18 \mathrm{mg}, 0.02 \mathrm{mmol})$ was added. The reaction was heated at $140{ }^{\circ} \mathrm{C}$ for $72 \mathrm{~h}$. Bromobenzene $(19 \mathrm{mg}, 0.1 \mathrm{mmol})$ was then added. The reaction was heated at $140{ }^{\circ} \mathrm{C}$ for $12 \mathrm{~h}$. Phenylboronic acid $(15 \mathrm{mg}, 0.1 \mathrm{mmol})$ was added and the reaction mixture was again heated at $140{ }^{\circ} \mathrm{C}$ for $12 \mathrm{~h}$. The mixture was cooled and added dropwise to $\mathrm{MeOH}$. After a few days at $4{ }^{\circ} \mathrm{C}$, the methanol solution was filtered and the residue was dissolved in $\mathrm{CHCl}_{3}$, and added drop by drop to a large volume of $\mathrm{MeOH}$. After a few days at $4{ }^{\circ} \mathrm{C}$, the methanol solution was filtered. The solid was further purified by Soxhlet extraction with acetone for 2 days. P1 was obtained as a yellow product (120 mg, 77\% yield).

${ }^{1} \mathrm{H}$ NMR $\left(300 \mathrm{MHz}, \mathrm{CDCl}_{3}, \delta\right) 9.32(\mathrm{br}, 4 \mathrm{H}$, bpm), $7.96(\mathrm{~d}, J=4.8 \mathrm{~Hz}, 2 \mathrm{H}$, aromatic fluorene), 7.62-7.75 (m, 4H, aromatic fluorene), 1.10 (br, 13H, alkyl), 0.77 (br, 13H, alkyl).

${ }^{13} \mathrm{C}$ NMR $\left(75 \mathrm{MHz}, \mathrm{CDCl}_{3}, \delta\right) 160.8,156.0,152.7,141.4,134.4,133.3,126.5,121.5,121.3$, $55.9,40.1,31.4,29.5,23.9,22.5,14.0$.

The fluorene/bipyrimidine ratio was confirmed to be 50\% according to the ${ }^{1} \mathrm{H}$ NMR spectrum. GPC measurements afforded values of 3.55 and $4.63 \mathrm{kDa}$, for $M_{n}$ and $M_{w}$, respectively, leading to a dispersity of 1.31 .

Poly((2,2'-bipyrimidine)-alt-3,6-(9-hexyl-9H-carbazole)) (P2). P2 was prepared in 52\% yield from 5,5'-dibromo-2,2'-bipyrimidine and 9-hexyl-3,6-bis(4,4,5,5-tetramethyl-1,3,2dioxaborolan-2-yl)-9H-carbazole by a method similar to that described for P1.

${ }^{1} \mathrm{H}$ NMR $\left(300 \mathrm{MHz}, \mathrm{CDCl}_{3}, \delta\right) 9.40(\mathrm{~d}, J=3.0 \mathrm{~Hz}, 4 \mathrm{H}$, bpm), 8.55 (d, $J=3.0 \mathrm{~Hz}, 2 \mathrm{H}$, aromatic carbazole), $7.85(\mathrm{br}, 2 \mathrm{H}$, aromatic carbazole), $7.64(\mathrm{t}, J=5.1 \mathrm{~Hz}, 2 \mathrm{H}$, aromatic carbazole), $4.42\left(\mathrm{t}, J=6.0 \mathrm{~Hz}, 2 \mathrm{H}, \mathrm{N}-\mathrm{CH}_{2}\right), 1.95\left(\mathrm{br}, 2 \mathrm{H}, \mathrm{CH}_{2}\right), 1.33\left(\mathrm{~m}, 6 \mathrm{H}, \mathrm{CH}_{2}\right), 0.88$ (br, $\left.3 \mathrm{H}, \mathrm{CH}_{3}\right)$. 
${ }^{13} \mathrm{C}$ NMR (75 MHz, $\left.\mathrm{CDCl}_{3}, \delta\right)$ 162.6, 160.3, 155.9, 141.4, 125.3, 123.6, 122.2, 119.6, 119.2, $110.3,31.6,29.7,29.0,27.0,22.6,14.1$.

The carbazole/bipyrimidine ratio was determined to be $50 \%$ as the relative intensities for the bpm and carbazole aromatic protons are 4 and 6, respectively.

$M_{n}=1.87 \mathrm{kDa}$ and $M_{w}=2.68 \mathrm{kDa}$, leading to a polydispersity of 1.43 .

Preparation of the sol-gel soft material. 9-(3-(triethoxysilyl)propyl)carbazole (170 mg, $0.45 \mathrm{mmol}$ ) was stirred at $50{ }^{\circ} \mathrm{C}$ and then a drop of triethylamine was added to initiate the hydrolysis and condensation reactions. The final material was obtained as a yellow liquid after 15 min of stirring.

Formation of the Si-O-Si framework was evidenced by infra-red spectroscopy: $v_{\text {as }}(\mathrm{Si}-\mathrm{O})$ : $\sim 1076 \mathrm{~cm}^{-1} ; v_{\mathrm{s}}(\mathrm{Si}-\mathrm{O}): \sim 796 \mathrm{~cm}^{-1} ; \delta(\mathrm{Si}-\mathrm{O}-\mathrm{Si}):$ at $\sim 447 \mathrm{~cm}^{-1}$. The absorption band around 1618 $\mathrm{cm}^{-1}$ is related to the stretching vibration of $v_{\mathrm{as}}(\mathrm{C}=\mathrm{C})$. A broad band around $3427 \mathrm{~cm}^{-1}$ is ascribed to the stretching vibration of $\mathrm{H}_{2} \mathrm{O}$ groups.

2.3. NMR. NMR spectra have been recorded on a Bruker Advance 300 spectrometer using $\mathrm{CDCl}_{3}$ as the solvent; chemical shifts are given with respect to TMS $(\delta=0)$.

2.4 Mass spectrometry. Mass spectrometry experiments were recorded on tims-TOF mass spectrometer (Bruker, France). Compound are solubilized in THF, then diluted in $\mathrm{CH}_{3} \mathrm{CN}$ with $0.1 \%$ formic acid at $10^{-6} \mathrm{M}$ and introduced at $5 \mu \mathrm{L} \cdot \mathrm{min}^{-1}$ flow rate into the electrospray ion source in positive mode (ESI-P). Capillary and end plate voltages were set at $4.5 \mathrm{kV}$ and $0.5 \mathrm{kV}$, respectively. Nitrogen was used as the nebulizer and drying gas at 2 bar and 8 L.min ${ }^{-1}$, respectively, with a drying temperature of $220^{\circ} \mathrm{C}$. Full scan (MS) have been carried. Tuning mix (Agilent, France) was used for calibration. Accurate masses and elemental compositions were obtained using the DataAnalysis software. The elemental compositions were obtained with a tolerance below $3 \mathrm{ppm}$. 
2.5. Thermogravimetic Analyses (TGA). They were made on a Netzsch STA 409 PC Luxx ${ }^{\circledR}$ analyser under a $\mathrm{N}_{2} / \mathrm{O}_{2}$ atmosphere at a rate of $10^{\circ} \mathrm{C} / \mathrm{min}$.

2.6. Differential Scanning Calorimetry (DSC). Differential scanning calorimetry (DSC) analyses were performed with a Mettler Toledo DSC 3 STARe system instrument. A heating program with a rate of $10^{\circ} \mathrm{C} / \mathrm{min}$ was employed in the temperature range between 30 ${ }^{\circ} \mathrm{C}$ and $280{ }^{\circ} \mathrm{C}$. For each DSC experiment, 5 to $15 \mathrm{mg}$ of the luminophore powder was placed in a $40 \mu \mathrm{l}$ aluminum pan.

2.7. Electronic spectroscopy. UV-Vis absorption spectra were recorded using a Jenway UV-VIS Spectrophotometer Model UV 6800. THF and methylene chloride of spectroscopic grade were used as solvent.

Photoluminescence (PL) spectra were obtained using a HORIBA Jobin Yvon Spectrofluorometer Model Fluoromax-4. Quantum yield efficiencies were measured using a C9920-02G PL-QY integrating sphere measurement system from Hamamatsu Photonics. The setup consisted of a $150 \mathrm{~W}$ monochromatized Xe lamp, an integrating sphere (Spectralon coating, $\varnothing=3.3$ in.) and a high-sensitivity CCD camera.

\subsection{Photostability studies.}

Samples preparation is detailed in the Supporting Information part.

The photostability studies were carried out using a home-made setup consisting of a powercontrolled UV LED emitting at $375 \mathrm{~nm}$ as excitation source and a HR4000 high resolution spectrometer (Ocean Optics) as PL analyzer. The emission spectra of the composite films were collected every $20 \mathrm{~min}$ up to $100 \mathrm{~h}$. Their area was integrated to obtain the total emission intensity. The LED power was measured using a Scientech Model Mentor MA 10 with a MC2501 calorimetric head unit (25.4 $\mathrm{mm}$ aperture). The measurement was performed by centering the head unit over the LED source and measuring the LED power of light emitted through the aperture. The UV LED power was $1.2 \mathrm{~mW}$. The power density of LED 
can be expressed in $\mathrm{W} / \mathrm{m}^{2}$ and was calculated by LED power (in watt) per unit surface of sample $\left(0.25 \mathrm{~cm}^{2}\right)$. According to our experiment, the power density of LED was $48 \mathrm{~W} / \mathrm{m}^{2}$ for UV LED emitting at $375 \mathrm{~nm}$. The power density was modulated to 7 and $15 \mathrm{~W} / \mathrm{m}^{2}$ by adding neutral filters.

\section{RESULTS AND DISCUSSION}

3.1. Synthesis. Polymers P1 and P2 were designed in order to introduce 2,2'bipyrimidine (bpm) as an electron-deficient unit into the backbone of conjugated (D-A)n polymers that had never been used before for such purpose. It was regularly alternated with the electron-rich 2,7-dihexyl fluorene and 3,6-hexyl carbazole units in P1 and P2, respectively. The synthesis of $\mathbf{P 1}$ and $\mathbf{P 2}$ is depicted on Scheme 1. To the best of our knowledge, no soluble organic polymer comprising 2,2'-bipyrimidine units inserted in a controlled manner into the backbone was known when we embarked in this project. The only report that could be found in the literature was about the formation of poly(pyrimidine-2,5diyl) starting from 2,5-bromopyrimidine. ${ }^{36}$ This polymer was described to be only soluble in concentrated acids such as $\mathrm{HCl}, \mathrm{HNO}_{3}$, or $\mathrm{H}_{2} \mathrm{SO}_{4}$. Further, we previously showed that bpm could lead to materials with interesting luminescent properties. ${ }^{28-31}$ The initial purpose of this work was thus to both reduce the bandgap of a blue-emitting polyfluorene and polycarbazole homopolymers in order to generate a red-shifted emission and to develop the chemistry of conjugated polymers with 2,2'-bipyrimidine as a new building block.

P1 was obtained in $77 \%$ yield. ${ }^{1} \mathrm{H}$ NMR spectroscopy confirmed the bpm:fluorene ratio of 1:1. Indeed, the aromatic signal related to the protons of bpm integrated for $4 \mathrm{H}$ and the relative integral for the two signals corresponding to the aromatic protons of the fluorene unit 
was $6 \mathrm{H}$. As will be shown later, $\mathbf{P 1}$ is poorly photostable under the powerful irradiation conditions that we used. Thus, $\mathbf{P 2}$ was designed to have a clue on the difference in photostability when switching from 2,7-fluorene to 3,6-carbazole. For the sake of clarity, it will consequently be presented along with $\mathbf{P 1}$. The bpm:carbazole ratio of 1:1 in $\mathbf{P 2}$ was also confirmed by NMR spectroscopy.

3.2. Thermal properties. As the temperature of a working LED can easily reach $50^{\circ} \mathrm{C}$, an important parameter to be studied is the behavior of the luminescent materials with temperature. Thermogravimetric (TGA) analysis of $\mathbf{P 1}$ and $\mathbf{P 2}$ have thus been performed. The curves obtained under a mixture of oxygen and nitrogen are reported on Figure 1a. They show a very similar behavior in the range of interest, especially, the two polymers are stable up to $250{ }^{\circ} \mathrm{C}$. Note that the curve corresponding to $\mathbf{P 2}$ shows a mass loss of about $7 \%$ around 100 ${ }^{\circ} \mathrm{C}$, which indicates that water was present in the sample studied, but this mass loss does not correspond to any degradation of the polymer.

The emission of conjugated polymers can be influenced by the supramolecular organization. ${ }^{32}$ In particular, it is of importance to identify the glass transition temperature as it can occur within the LED working temperature range. DSC studies were then performed on $\mathbf{P 1}$ and $\mathbf{P 2}$ in order to determine if there was any observable phase transition. The DSC curves are reported on Figure $1 \mathrm{~b}$ and 1c. The curve obtained for $\mathbf{P} \mathbf{1}$ revealed an endothermic peak at $150.3{ }^{\circ} \mathrm{C}$ (with an associated variation of enthalpy $\Delta H_{G}$ of $0.77 \mathrm{~J} / \mathrm{g}$ ) corresponding to the glass transition temperature, while crystallization occurred at $169.9{ }^{\circ} \mathrm{C}\left(\Delta H_{\text {crys }}=19.54 \mathrm{~J} / \mathrm{g}\right)$. These data indicate that no phase transition occurred below $150{ }^{\circ} \mathrm{C}$. This is an important information as it shows that no change in the arrangement of the polymer chains that could modify the emission will occur. This ensures the stability of the operating device in terms of emission 
color. Only crystallization could be observed on the DSC curve of $\mathbf{P 2}$ at $163.3{ }^{\circ} \mathrm{C}\left(\Delta H_{\text {crys }}=\right.$ $51.73 \mathrm{~J} / \mathrm{g})$
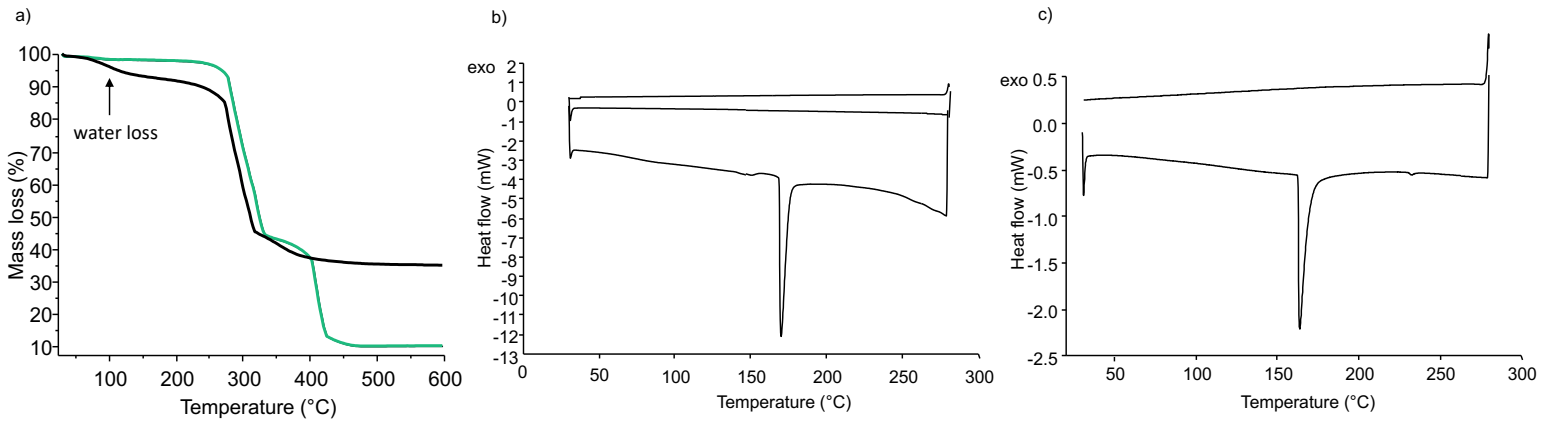

Figure 1. a) TGA curves of $\mathbf{P 1}$ (green trace) and $\mathbf{P} 2$ (black line) under an $\mathrm{O}_{2} / \mathrm{N}_{2}$ atmosphere; b) DSC curves for P1; and c) DSC curves for P2.

\subsection{Photophysical properties.}

In order to have a rapid clue on the ability of $\mathbf{P 1}$ and $\mathbf{P 2}$ to act as potential light converters and to probe their emission color, we have performed preliminary investigations on solutions. Emission and excitation spectra of $\mathbf{P 1}$ and $\mathbf{P 2}$ are reported on Figure 2, as well as those of poly(9,9-dihexylfluorene-2,7-diyl), PF, and poly(9-hexyl carbazole-3,6-diyl), PCz, for comparison. The absorption spectrum of $\mathbf{P 1}$ recorded at a concentration of $0.01 \mathrm{mg} / \mathrm{mL}$ in dichloromethane shows a broad band ranging from 300 to $420 \mathrm{~nm}$, with a maximum at 373 $\mathrm{nm}$ and a shoulder at $385 \mathrm{~nm}$ (Figure 2a). The low-energy shoulder can be attributed to the intramolecular charge transfer between donor and acceptor units. Investigations on the emission properties have then been done with the same solution (i.e. same concentration) for the following reason: to be sure to obtain emission of single polymer chains without any aggregations, and thus to get insight into the intrinsic emission properties of the polymer, it is 
necessary to avoid any interaction between molecules of polymer. This is why we have been working with a very diluted solution $(0.01 \mathrm{mg} / \mathrm{mL}$ in dichloromethane). The emission spectrum of the solution of P1 was recorded after excitation at $375 \mathrm{~nm}$ (Figure 2a). It comprises an overall band in the range 400-650 nm with a maximum at $475 \mathrm{~nm}$ and a shoulder at $430 \mathrm{~nm}$, marked with an asterisk on the spectrum. This broad band is responsible for the green light emitted by this solution with CIE coordinates of $(0.24,0.39)$ (Figure S2a). Note that the concentration of $0.01 \mathrm{mg} / \mathrm{mL}$ has been determined after recording the emission spectra of solutions with different concentrations. In fact, when the intensity of emission was reported $v s$ concentration, a linear domain was observed for concentrations lower than 0.02 $\mathrm{mg} / \mathrm{mL}$ (Figure S3, left, Supporting Information). This linear domain is indicative of noninteraction between molecules in solution.

The excitation spectrum (Figure $2 \mathrm{a}$ ) shows a band from 300 to $430 \mathrm{~nm}$ with a maximum at $364 \mathrm{~nm}$ and a shoulder at $380 \mathrm{~nm}$. It is very similar to the absorption spectrum described above, showing that the absorbing state is also the emitting one. Especially, the position and shape of the excitation spectrum are independent on the analysis wavelength (Figure S4a, Supporting Information) confirming the existence of a unique emitting state. This was also confirmed by the emission spectra recorded at different excitation wavelengths which showed the same emission band (Figure S4b, Supporting Information). For the sake of comparison, spectra of PF are also reported on Figure 2c. These data clearly demonstrate that the introduction of bpm into the backbone of PF in an alternating manner resulted in a red-shift of the emission.

Investigations on the photophysical properties of $\mathbf{P 2}$ are also reported on Figure $2 \mathrm{~b}$. $\mathbf{P 2}$ shows absorption mainly in the near UV, with a maximum at $379 \mathrm{~nm}$ and up to $450 \mathrm{~nm}$. The emission spectrum is made of a band ranging from 420 to $600 \mathrm{~nm}$ which possesses a maximum at $473 \mathrm{~nm}$, resulting in a green color of emission with CIE coordinates $(0.25,0.40)$ which are similar to those recorded for P1. Also, comparison of the photophysical properties 
of $\mathbf{P 2}$ with those of the parent poly(3,6-hexyl carbazole) previously reported, ${ }^{16}$ showed a redshift for P2, which is due to the electronic interaction between bpm and 3,6-carbazole. These results show that replacing 2,7-fluorene units with 3,6-carbazole moieties in the polymer backbone only resulted in slight changes in the absorption range and color of emission, showing similar conjugation lengths for both polymers. The intrinsic properties of $\mathbf{P F}, \mathbf{P C z}$, $\mathbf{P 1}$ and $\mathbf{P 2}$ are summarized in Table 1.

d)

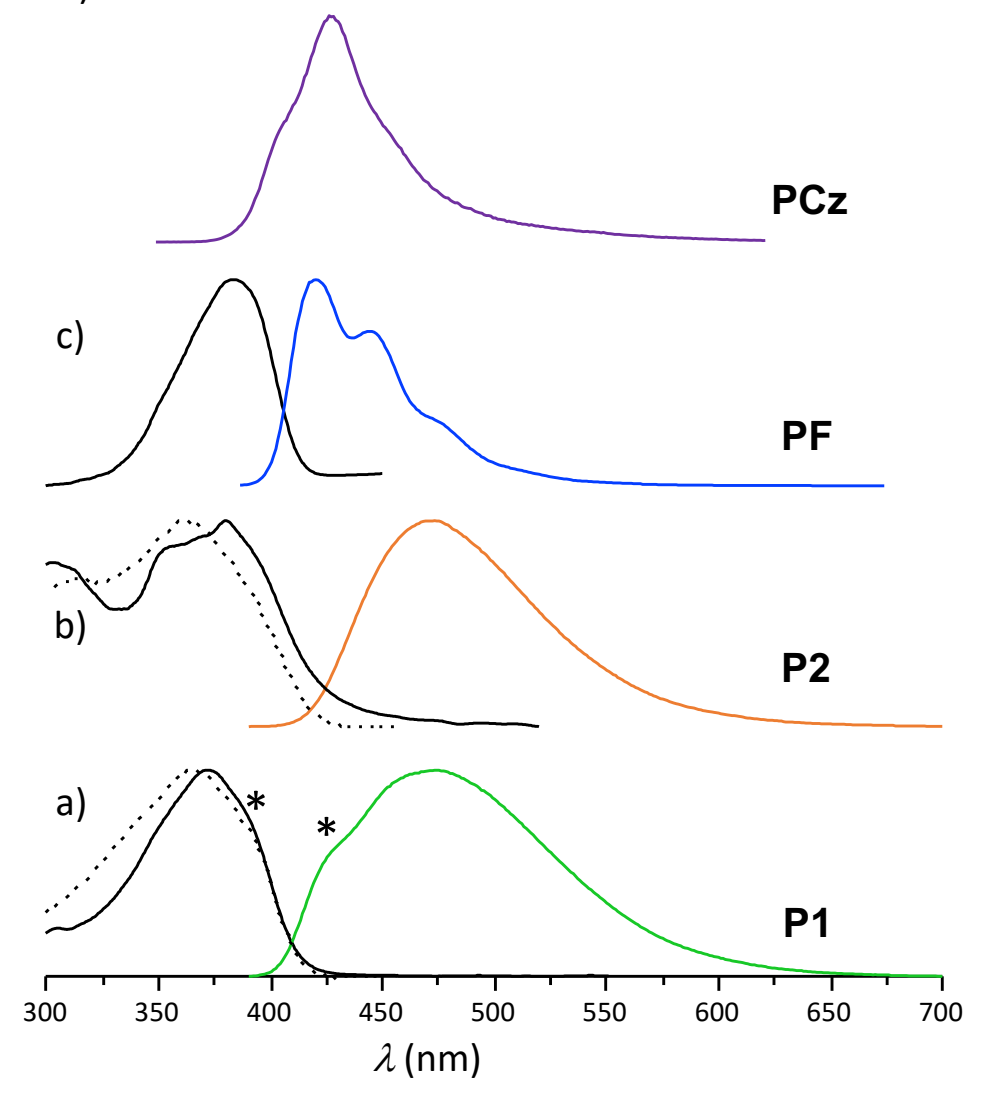

Figure 2. Normalized absorption, emission (colored traces: P1: green, P2: orange; PF: blue; PCz: purple)), and excitation spectra (dashed trace) for: a) $\mathbf{P 1}$; b) $\mathbf{P 2}$, c) $\mathbf{P F} \mathbf{F}^{16}$, and d) $\mathbf{P C} \mathbf{z}^{16}$ in $\mathrm{CH}_{2} \mathrm{Cl}_{2}$. Emission spectra were recorded with $\lambda_{\text {exc }}=375 \mathrm{~nm}(\mathbf{P 1}, \mathbf{P 2}, \mathbf{P F})$ and $320 \mathrm{~nm}$ for PCz; excitation spectra were recorded with $\lambda_{\mathrm{em}}=474 \mathrm{~nm}(\mathbf{P 1}), 470 \mathrm{~nm}(\mathbf{P 2}), 418 \mathrm{~nm}(\mathbf{P F})$, $420 \mathrm{~nm}(\mathbf{P C z})$. Concentrations are $0.01 \mathrm{mg} / \mathrm{mL}$ for P1, P2, PCz and $0.005 \mathrm{mg} / \mathrm{mL}$ for PF. 
Table 1. Photophysical properties of PF, PCz, $\mathbf{P 1}$ and $\mathbf{P 2}$ in $\mathrm{CH}_{2} \mathrm{Cl}_{2}$ (concentrations are 0.005 $\mathrm{mg} / \mathrm{mL}$ for $\mathbf{P F}$, and $0.01 \mathrm{mg} / \mathrm{mL}$ for $\mathbf{P 1}, \mathbf{P 2}$, and $\mathbf{P C z}$, respectively. All data are corresponding to their maxima in the spectra).

\begin{tabular}{cccc}
\hline Polymer & $\lambda_{\text {abs }}(\mathrm{nm})$ & $\lambda_{\text {exc }}(\mathrm{nm})$ & $\lambda_{\mathrm{em}}(\mathrm{nm})$ \\
\hline PF $^{16}$ & 380 & 360 & 418,444 \\
P1 & 373 & 364 & 475 \\
P2 & 379 & 362 & 473 \\
PCz & & 320 & 420 \\
\hline
\end{tabular}

Variations in the external photoluminescence quantum yields as a function of the excitation wavelengths are shown in Figure 3 for $\mathbf{P 1}$ and $\mathbf{P} 2$ in dichloromethane $(0.01 \mathrm{mg} / \mathrm{ml})$. The external photoluminescence Quantum Yields (eQY) is defined as the product of internal Quantum Yields (iQY) (which represents the number of emitted photons divided by the number of absorbed photons) and absorbance (Abs) (Abs, i.e. the number of absorbed photons divided by the number of exciting photons). As illustrated on Figure 3, the both polymers can be excited over a wide range of wavelengths in the range $300-400 \mathrm{~nm}$ to give efficient luminescence. Indeed, eQY values of $45.0 \%$ and $37.0 \%$ were found after excitation at $375 \mathrm{~nm}$ (corresponding to a UV commercial LED) for $\mathbf{P 1}$ and $\mathbf{P 2}$, respectively. They indicate that these two polymers emit with a relatively high efficiency. Overall, a compromise between a high internal photoluminescence quantum yield while maintaining an appropriate absorbance should be found. 

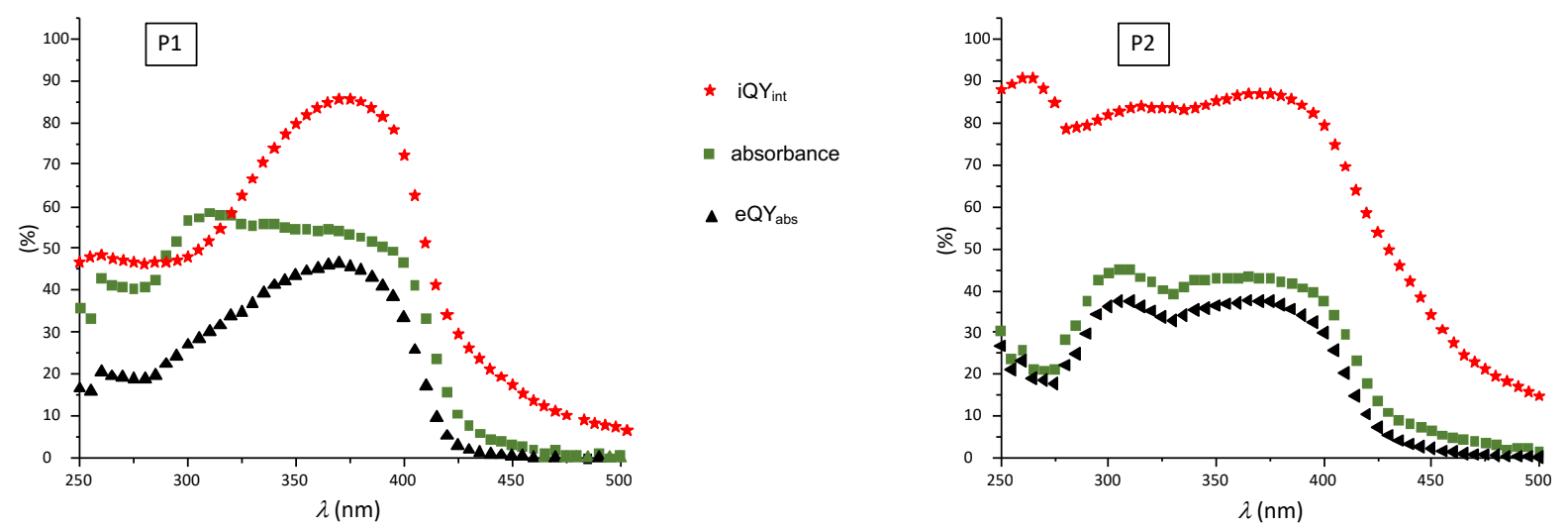

Figure 3. Variation in external photoluminescence quantum yield eQYabs (black trace), internal photoluminescence quantum $\mathrm{QQY}_{\text {int }}$ (green trace) and absorbance (red trace) as a function of the excitation wavelength for (left) $\mathbf{P 1}$ and (right) $\mathbf{P 2}$ in $\mathrm{CH}_{2} \mathrm{Cl}_{2}$ at $0.01 \mathrm{mg} / \mathrm{mL}$.

We describe hereafter our investigations on the potential use of these bpm-containing polymers to design materials for white light emission. P1 is taken as a representative example.

White light emitting materials. $\mathrm{A}_{\mathrm{CH}_{2}} \mathrm{Cl}_{2}$ solution obtained by mixing solutions of $\mathbf{P F}, \mathbf{P 1}$, and a europium complex (Figure S1) we have previously reported $^{38}$ in a v:v:v ratio of 3:20:350 was prepared. The emission spectrum recorded upon excitation at $375 \mathrm{~nm}$ is shown on Figure 4a. The emission of each component can be observed and the maxima are labeled with the codes used for each compound. In particular, the blue emission from polyfluorene is observed. This is an interesting point as red emitters usually absorb the emission of the blue emitters because of some overlap between the emission spectrum of the blue emitter and the absorption spectrum of the red emitter. Here, using a europium complex that strongly absorbs in the near-UV and shows a large Stokes shift avoided efficient absorption of the polyfluorene emission. Also, it is possible here that $\mathbf{P 1}$ absorbs a part of the light emitted by $\mathbf{P F}$, but, if so, it is not that important as the emission of $\mathbf{P F}$ is still observed while it is present in a minor quantity. If $\mathbf{P 1}$ was to absorb efficiently the blue light emitted by $\mathbf{P F}$, the relative quantity of PF would be much higher. The CIE coordinates were $(0.31,0.33)$ with a color temperature of 
ca. $6500 \mathrm{~K}$, corresponding to daylight (CIE coordinates were respectively for P1, PF and $\left.\mathbf{E u}(\text { tta })_{3} \mathbf{L} \quad:(0.24,0.39),(0.16,0.06),(0.62,0.34)\right)$.
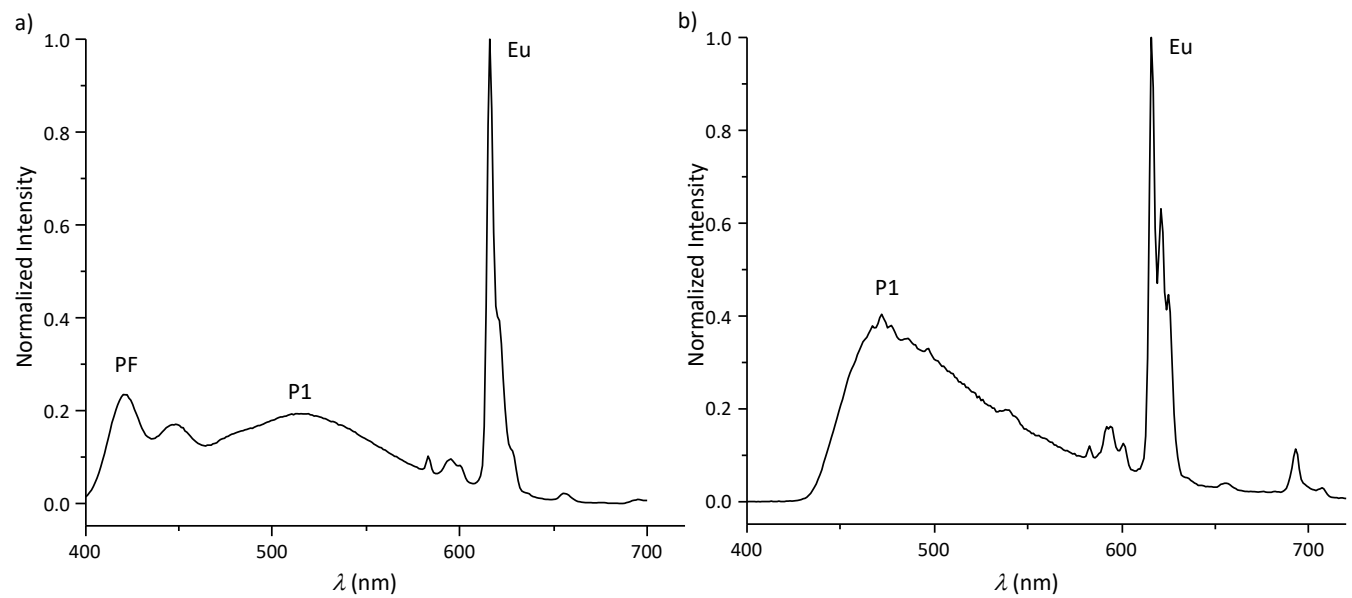

Figure 4. a) normalized emission spectrum of a $\mathrm{CH}_{2} \mathrm{Cl}_{2}$ solution obtained by mixing solutions of PF, P1, and the Eu complex $\left[\mathbf{E u}(\mathbf{t t a})_{3} \mathbf{L}\right]$ at concentrations $0.01 \mathrm{mg} / \mathrm{mL}$ in a v:v:v ratio $3: 20: 350\left(\lambda_{\mathrm{exc}}=370 \mathrm{~nm}\right)$; b) normalized emission spectrum of a film obtained upon mixing $13 \mathrm{mg}$ of $\mathbf{P 1}$ and $27 \mathrm{mg}$ of $[\mathrm{Eu}]$ in $600 \mathrm{mg}$ of $\mathbf{C z}-\mathbf{S i}\left(\lambda_{\mathrm{exc}}=375 \mathrm{~nm}\right)$.

Blending several compounds in the solid state can lead to phase separation. This is detrimental to the stability of the initial emission color and intensity. To overcome this problem and with the aim of decreasing the number of emitters, we have designed a viscous solvent-free blend free of PF as follows. We prepared a film comprising P1 (13 mg), the Eu complex (27 mg), and $500 \mathrm{mg}$ of the liquid sol-gel precursor Cz-Si. The liquid sol-gel material was chosen as part of the phosphor as it is well-suited for optical applications thanks to its transparency and sol-gel materials are known to protect the emitter from UV degradation. ${ }^{23}$ We focused on a liquid/soft matrix instead of a solid one because it can easily be coated on substrates of different shapes and it can be used to design foldable devices, thanks to its ability to form continuous and crack-free layers. Also, it does not require any 
solvent to be deposited, thus limiting the environmental impact if used at a large scale. Despite these advantages, luminescent organic and hybrid materials that present a liquid character have only been scarcely described. ${ }^{39}$ The emission spectrum of this coating is given on Figure 4b. It exhibits emission from both P1 (maximum at $472 \mathrm{~nm}$ ) and the Eu complex (maximum at $616 \mathrm{~nm}$ ). This resulted in a white color with CIE coordinates and a color temperature comparable to those recorded for the mixture comprising $\mathbf{P F}, \mathbf{P 1}$ and $\mathrm{Eu}$ complex, and corresponding to cool white light.

The above results show that $\mathbf{P F}$ and P1, a representative polymer that comprises 2,2'bipyrimidine, can be used to design white-emitting materials. This encouraged us to go one step further towards applications and study the possibility to use these polymers for the design of hybrid phosphors for near-UV LEDs. For such applications, the materials should show a satisfying photostability, that is, the photometric parameters should not shift when operating and the intensity should be stable.

Phosphors for LED lighting. We primarily studied the stability of PF under near-UV light. Polyfluorene derivatives have long been described as highly blue emitters, justifying the interest they aroused, especially in the design of polymer light emitting diodes. ${ }^{40} 150 \mathrm{mg}$ of a phosphor made of PF embedded into the liquid sol-gel material (at a concentration of 1.2 $\mathrm{wt} \%$ ) was embedded into $7.9 \mathrm{~g}$ of PMMA. Details on the preparation of composite films are given in the Supporting Information part.

In order to assess the stability of this PMMA hybrid composite film in operating conditions close to those in LED devices, it was irradiated by a UV LED (375 nm, power: $\left.15 \mathrm{~W} / \mathrm{m}^{2}\right)$ during 360 minutes in a black chamber at $22{ }^{\circ} \mathrm{C}$. The emission spectrum was recorded each 20 minutes and the evolution of integrated area of the emission spectrum was plotted as a function of the irradiation time. This evolution of this area is reported on Figure 5a, as well as that the whole emission spectrum (Figure 5b). The intensity dropped down to $c a .0 \%$ of the 
initial intensity after $25 \mathrm{~h}$ of exposure. This dramatic decrease clearly indicates that $\mathbf{P F}$ is not suited for being used as a blue phosphor for LED lighting applications. When exposed at a lower LED power $\left(7 \mathrm{~W} / \mathrm{m}^{2}\right)$, the decrease was slower, but still substantial, as $18 \%$ of the initial intensity remains after $25 \mathrm{~h}$ of illumination. Note that the emission spectrum recorded at different times showed an increase of a broad band centered at $525 \mathrm{~nm}$. The origin of this band has long been debated in the literature. Investigations for explaining this drift in color and decrease in intensity of polyfluorenes emission have led to the conclusions that exposure to air, heat treatment, or aggregation ${ }^{41}$ were responsible to the green emission. In particular, the formation of "fluorenone defects" because of the simultaneous presence of air and UV was demonstrated. ${ }^{42-44}$
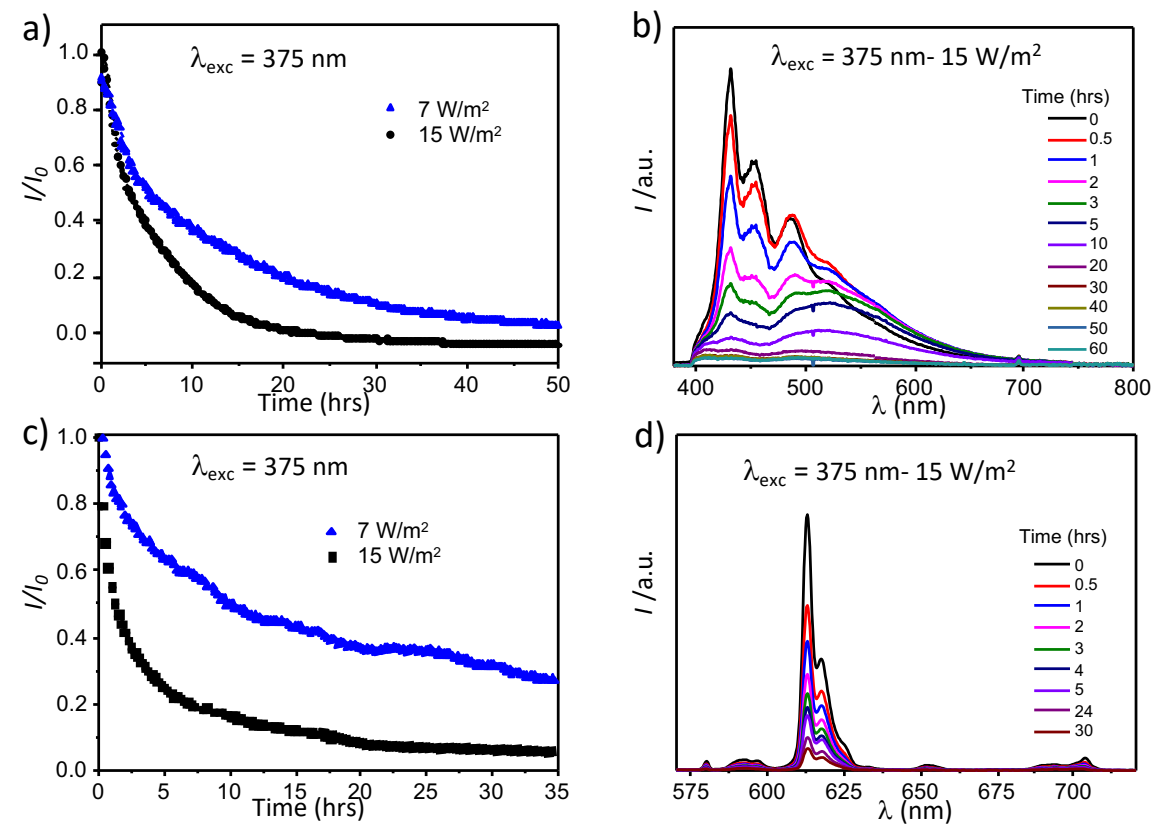

Figure 5. a) decay curve for $I / I_{o}$ of PF + liquid sol-gel in PMMA obtained at 7 and $15 \mathrm{~W} / \mathrm{m}^{2}$ under $375 \mathrm{~nm}$ irradiation; b) Evolution of the corresponding emission spectrum; c) decay curve for $I / I_{o}$ of Eu complex + liquid sol-gel in PMMA obtained at 7 and $15 \mathrm{~W} / \mathrm{m}^{2}$ under 375 $\mathrm{nm}$ irradiation; d) Evolution of the corresponding emission spectrum. 
As already mentioned, white LEDs usually combine yellow and red phosphors to generate a warm white light. Many applications require spectral responses close to those of the light of day, but it is difficult to achieve this with blue LEDs combined with phosphors. The combination of UV LEDs with several phosphors offers more potential. In addition, there are more red phosphors that can be efficiently excited by UV LEDs than by blue LEDs. The development of long-wavelength emitters, and in particular those which emit in the red, is thus of primary importance in order to develop lighting devices with a color rendering index approaching that of daylight. The photostability of the highly red-emissive europium complex ${ }^{38}$ previously used was then investigated. A similar experiment to that described for PF was performed in order to evaluate the behavior of the europium complex under a UV stress (Figure 5c). A phosphor comprising $32 \mathrm{mg}$ of the europium complex and $600 \mathrm{mg}$ of $\mathbf{C z}-$ Si was prepared. It was embedded at $0.4 \mathrm{wt} \%$ into PMMA and this composite was deposited as a film. After $25 \mathrm{~h}$ of continuous illumination at a power of $15 \mathrm{~W} / \mathrm{m}^{2}$ at $22{ }^{\circ} \mathrm{C}$, the intensity of the Eu complex dropped down to $8 \%$ of the initial intensity. As observed with PF, the decrease in LED power leads to a slowing down of the loss in intensity, which was close to $40 \%$ for a UV LED power of $7 \mathrm{~W} / \mathrm{m}^{2}$. Note that no drift in the emission color was observed for the Eu complex. This measurement showed that, unfortunately, the europium complex did not show either a satisfactory stability for being used as an emitter for the elaboration of a hybrid LED phosphor. It should be noted that the results recorded with a LED power of 48 $\mathrm{W} / \mathrm{m}^{2}$ are not presented because the loss of light emission properties takes place from the first minutes of irradiation and this for the two mixtures that we have just presented.

The fact that $\mathbf{P 1}$ and $\mathbf{P 2}$ both possess a maximum of absorption close to $375 \mathrm{~nm}$ is encouraging for investigating them as emitters in the design of visible-emitting phosphors for 375 nm-UV commercial LEDs. The photostability of P1 was then probed under UV exposure. A luminescent composite film (named P1c in the remainder of this paper) was designed by embedding P1 into PMMA at $0.16 \mathrm{wt} \%$. The film was then irradiated with a $375 \mathrm{~nm}-\mathrm{LED}$ at a 
power as high as $48 \mathrm{~W} / \mathrm{m}^{2}$. We conducted the experiment at such a high power, as, unlike what was observed for PF and the Eu complex, the emission decay was still observable. This is a primary indication on an improved photostability of $\mathbf{P 1}$ and $\mathbf{P 2}$ with respect to $\mathbf{P F}$ and the Eu complex. The evolution of the intensity of emission over the initial intensity with time is reported on Figure 6, curve a. It exponentially decreased to reach a stable intensity of only $9 \%$ of the initial intensity after $40 \mathrm{~h}$. In order to improve this value, we have added the liquid solgel material to the composition of the phosphor. Then, a phosphor made from $10 \mathrm{mg}$ of $\mathbf{P 1}$ and $400 \mathrm{mg}$ of the sol-gel precursor $\mathbf{C z}-\mathbf{S i}$ was formed. It was embedded into PMMA at 0.16 $\mathrm{wt} \%$, and the stability of a film of this material was investigated upon irradiation by the 375 nm UV LED. As shown on the figure 6, curve c, the emission was stabilized after $40 \mathrm{~h}$ of operation at a value of $27 \%$ of the initial intensity. Incorporating the sol-gel matrix into the phosphor thus resulted in a 3-fold enhancement of the photostability of the phosphor.

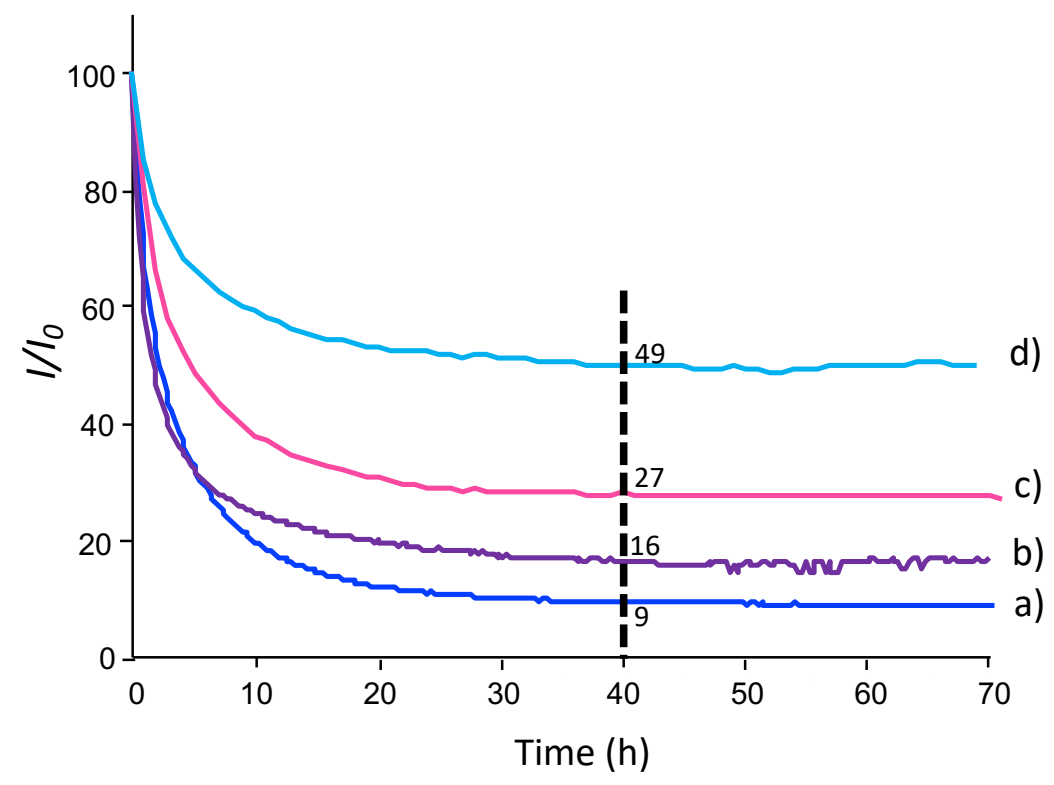

Figure 6. $I / I_{o}$ versus time of films containing: a) P1 in PMMA; b) P1 + liquid sol-gel in PMMA, c) $\mathbf{P 2}$ in PMMA, d) P2 + liquid sol-gel in PMMA. I represents the maximum of emission, $I_{o}$ is the intensity of the maximum of emission of each film at $\mathrm{t}=0$. Films were irradiated at $48 \mathrm{~W} / \mathrm{m}^{2}$ with $375 \mathrm{~nm}$ UV LED. See text for the exact composition of the films. 
Among conjugated polymers comprising different units in their backbone, polyfluorene derivatives have been reported to be relatively highly sensitive to UV light degradation in the presence of oxygen, ${ }^{22}$ while carbazole was described to be somewhat more stable. A stability study similar to that described for $\mathbf{P 1}$ was conducted for P2. As described above, the emission properties of $\mathbf{P} \mathbf{2}$ were comparable to that of $\mathbf{P 1}$ in terms of color of light. In order to check the photostability of $\mathbf{P 2}$ under UV light, a composite film (named P2c) made of $1.58 \mathrm{mg}$ of $\mathbf{P 2}$ dispersed into $0.988 \mathrm{~g}$ of PMMA was designed. As observed with P1c, stabilization of the emission was observed after 40 hours of irradiation with an intensity being $16 \%$ of the initial one (Figure 6, curve b). Even though this loss in intensity was still relatively important, it was improved of about 2 times compared to that of P1c in the same conditions. In order to improve this photostability, we further investigated the stability of a phosphor made from 10 $\mathrm{mg}$ of $\mathbf{P 2}$ and $400 \mathrm{mg}$ of the liquid sol-gel precursor embedded into PMMA at $0.16 \mathrm{wt} \%$. Figure 6 , curve d, shows that, after $c a$. $40 \mathrm{~h}$ of operation, the emission was stabilized at $49 \%$ of the initial emission intensity, giving rise to an improvement by a factor of 2 when using the sol-gel matrix, confirming the result obtained with P1c.

The evolution of the emission spectra with the irradiation time are shown in Figures $7 \mathrm{a}$ and b for the composite films P1c and P2c, respectively. In both cases the emission profiles are characterized by an asymmetric broadband ranging from 450 to over $650 \mathrm{~nm}$, covering a large part of the visible. A stronger contribution in the red is observed on Figure $7 \mathrm{~b}$. The asterisk on Figure $7 \mathrm{~b}$ marks is to show the presence of a shoulder at $560 \mathrm{~nm}$ that leads to a color point closer to that of the black body curve as illustrated by the positioning of the color point on the chromaticity diagram (Figure S2). In addition, the emission maximum observed at $500 \mathrm{~nm}$ is also blue-shifted with respect to the P1c composite (maximum at $510 \mathrm{~nm}$ ). The P2c composite covers a larger wavelength range in the visible, which also explains the position of its color point, which is more similar to the black body as mentioned above. 
With the irradiation time, a slight drift of the color point is observed in both cases, which results in a decrease of the spectral contribution in the longer wavelength range $(>510 \mathrm{~nm})$.

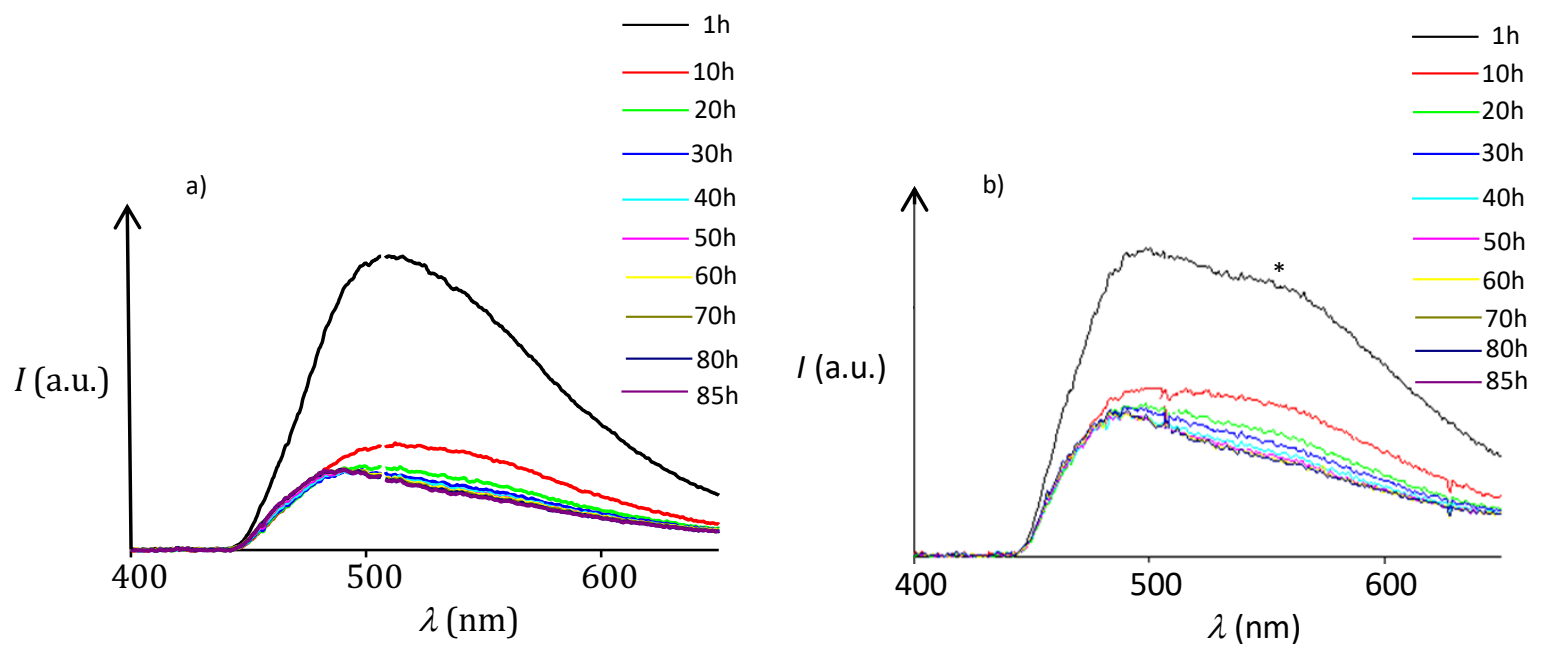

Figure 7. Evolution of the emission spectra with time of films deposited on $375 \mathrm{~nm}$ LED (LED power of $48 \mathrm{~W} / \mathrm{m}^{2}, 22{ }^{\circ} \mathrm{C}$ ) comprising: a) $\mathbf{P 1}$ and the liquid sol-gel matrix embedded into PMMA; b) P2 and the liquid sol-gel matrix embedded into PMMA. See text for the exact composition of the films.

Investigations on the stability of the phosphors presented above show that replacing 2,7dihexyl fluorene moieties by 3,6-hexyl carbazole lead to an improvement of the photostability by a factor of $c a .3$, and introducing the liquid sol-gel matrix in the composition of the phosphor resulted in an additional 2-fold enhancement of the photostability. This resulted in a phosphor showing an emission stabilized at half of its initial intensity under a relatively high power. Work is currently underway to both design new bpm-containing phosphors with tunable visible emission and improve their stability under UV light exposure. 


\section{CONCLUSIONS}

We have presented a new family of alternating conjugated polymers by introducing 2,2'bipyrimidine as an electron deficient unit into the backbone. It was regularly alternated with 2,7-dihexyl fluorene (P1) and 3,6-hexyl carbazole (P2) electron-rich units. The resulting polymers showed an interesting thermal stability (up to $250{ }^{\circ} \mathrm{C}$ under an $\mathrm{O}_{2} / \mathrm{N}_{2}$ atmosphere). As expected with the design of such donor-acceptor polymers, the bandgap was reduced as both the absorption and emission spectra were shifted to the red with respect to the parent polymer poly(2,7-dihexyl fluorene) and poly(3,6-N-hexyl carbazole). This resulted in greenish blue emissions for both polymers, showing that the strength of the donor-acceptor electronic interaction between the fluorene and 2,2'-bipyrimidine units on the one hand, and that between the carbazole and 2,2'-bipyrimidine units on the other hand, was similar. These two polymers showed intense absorption in the near UV, and high emission with quantum yields of $45.0 \%$ and $37.0 \%$ for $\mathbf{P 1}$ and $\mathbf{P 2}$, respectively. P1 was used as a representative example to obtain white emission. In particular, the broad emission of the polymer avoided the use of the blue-emitting PF, reducing the number of emitters in the design of the luminescent material.

Photostability studies were conducted to check whether the different emitters could be used in the design of phosphors for hybrid LED lighting. The 2,7-dihexyl fluorene moiety was shown to be too unstable under UV light irradiation, as well as the europium complex used for red emission. Thus, even though these compounds are highly emissive, they cannot be envisaged to be used for such application, especially as relatively high electrical powers are needed. Using 3,6-hexyl carbazole instead of 2,7-dihexyl fluorene afforded a more stable compound, as the photostability of $\mathbf{P} 2$ was improved by a factor of 3, with respect to that of P1. Incorporating an additional liquid sol-gel component into the design of the phosphors lead to a further improvement by a factor of $c a .2$ of the photostability. These studies showed that 
the photostability of the phosphors can be improved by both chemical and phosphor composition engineering.

\section{ASSOCIATED CONTENT}

\section{Supporting Information}

The Supporting Information is available free of charge at $\operatorname{xxxxxxxxxxx.}$

Supporting information contents include: CIE chromaticity coordinates, Intensity of the emission maximum of polymers with various concentrations, excitation and emission spectra of polymers varying the analysis wavelength.

\section{AUTHOR INFORMATION}

\section{Corresponding Author}

Email: gael.zucchi@polytechnique.edu.

\section{Author Contributions}

Qiqiao Lin has synthesized all molecules described in the paper, recorded emission and absorption spectra, and reviewed the manuscript. Xiaoguang Huang first synthesized the liquid material-related compounds. Sasikumar Ramachandran and Xinyang Wang participated in the synthesis of the two polymers. Rachod Boonsin, Rodolphe Valleix, and Yasmine Khendriche performed photostability measurements. Damien Boyer participated in the photostability measurements and in reviewing the manuscript. Jean-Philippe Roblin performed quantum yield determination and DSC measurements, and participated in the writing of the photostability part and reviewed the manuscript. Geneviève Chadeyron 
participated in the photostability studies and quantum yield measurements and reviewed the manuscript. Gaël Zucchi wrote the manuscript, did the TGA measurements, participated in the photophysical measurements and in the interpretation of the photophysical and photostability studies, and designed P1 and P2.

All authors have given approval to the final version of the manuscript.

\section{Notes}

Declarations of interest: none.

\section{ACKNOWLEDGMENTS}

We wish to thank Dr Gaëlle Pembouong for GPC measurements and Dr Sophie Bourcier for HRMS analysis. Ecole polytechnique and CNRS are acknowledged for their financial support. QL thanks the China Scholarship Council (NO. 201608350066) for a PhD fellowship, XW thanks LabEx CHARMMMAT (ANR-11-LABEX-0039) for a PhD grant, and SR thanks the EU for a postdoctoral grant (Grant agreement 644852).

\section{REFERENCES}

1. Zhou, Q.; Swager, T. M. Fluorescent chemosensors based on energy migration in conjugated polymers: the molecular wire approach to increased sensitivity. J. Am. Chem. Soc. 1995, 117, 12593-12602.

2. Joo, Y.; Huang, L.; Eedugurala, N.; London, A. E.; Kumar, A.; Wong, B. M.; Boudouris, B. W.; Azoulay, J. D. Thermoelectric performance of an open-shell donor-acceptor conjugated polymer doped with a radical-containing small molecule. Macromolecules 2018, 51, 3886-3894. 
3. Wu, C.; Hansen, S. J.; Hou, Q.; Yu, J.; Zeigler, M.; Jin, Y.; Burnham, D. R.; Mc Neill, J. D.; Olson, J. M.; Chiu, D. T. Design of highly emissive polymer dot bioconjugates for in vivo tumor targeting. Angew. Chem. Int. Ed. 2011, 50, 3430-3434.

4. Kim, S.; Lim, C. K.; Na, J.; Lee, Y. D.; Kim, K.; Choi, K.; Leary, J. F.; Kwon, I. C. Conjugated polymer nanoparticles for biomedical in vivo imaging. Chem. Commun. 2010, 46, 1617-1619.

5. Wu, W.; Bazan, G. C.; Liu, B. Conjugated-polymer-amplified sensing, imaging, and therapy. Chem. 2017, 2, 760-790.

6. Meng, Z.; Hou, W.; Zhou, H.; Zhou, L.; Chen, H.; Wu, C. Therapeutic Considerations and Conjugated Polymer-Based Photosensitizers for Photodynamic Therapy. Macromol. Rapid. Commun. 2018, 39, 1-15.

7. Ortiz, A. M. O.; George, O.; Jasim, K.; Gesquiere, A. J. Photodynamic Therapy with Conjugated Polymer Nanoparticles: Recent Advances and Therapeutic Considerations. $J$. Cancer Treatment Diagn. 2018, 2, 1-6.

8. Havinga, E. E.; Ten Hoeve, W.; Wynberg, H. A new class of small band gap organic polymer conductors. Polymer Bulletin 1992, 29, 119-126.

9. Piquette, A.; Bergbauer, W.; Galler, B.; Mishra, K. C. On choosing phosphors for near-UV and blue LEDs for white light. ECS J. Solid. State. Sci. Technol. 2015, 5, R3146-R3159.

10. Hide, F.; Kozodoy, P.; DenBaars, S. P.; Heeger, A. J. White light from InGaN/conjugated polymer hybrid light-emitting diodes. Appl. Phys. Lett. 1997, 70, 2664-2666.

11. Jin, G.; Lian, S.; Pan, Y.; Wu, Z.; Hu, D.; Mo, Y.; Liu, Li; Xie, Z.; Ma, Y. Effect of side chains on color purities of mono-triphenylamine-functionalized polyspirobifluorenes for pure blue polymer light-emitting diodes. Polym. Chem. 2019, 10, 494-502.

12. Sun, J.; Wu, D.; Gao, L.; Hou, M.; Lu, G.; Li, J.; Zhang, X.; Miao, Y.; Wang, H.; Xu, B. Polyfluorene-based white light conjugated polymers incorporating orange iridium(III) 
complexes: the effect of steric configuration on their photophysical and electroluminescent properties. RSC Adv. 2018, 8, 1638-1646.

13. Peng, F.; Li, N.; Ying, L.; Zhong, W.; Guo, T.; Cui, J.; Yang, W.; Cao, Y. Highly efficient single-layer blue polymer light-emitting diodes based on hole-transporting group substituted poly (fluorene-co-dibenzothiophene-S, S-dioxide). J. Mater. Chem C. 2017, 5, 9680-9686.

14. Bai, L.; Liu, B.; Han, Y.; Yu, M.; Wang, J.; Zhang, X.; Ou, C.; Lin, J.; Zhu, W.; Xie, L.; Yin, C.; Zhao, J.; Wang, J.; Bradley, D. D. C.; Huang, W. Steric-HindranceFunctionalized Polydiarylfluorenes: Conformational Behavior, Stabilized Blue Electroluminescence, and Efficient Amplified Spontaneous Emission. ACS Appl. Mater. Inter. 2017, 9, 37856-37863.

15. Park, J. S.; Jin, S. H.; Gal, Y. S.; Lee, J. H.; Lee, J. W. Synthesis and characterization of carbazole-based copolymers containing benzothiadiazole derivative for polymer lightemitting diodes. Mol. Cryst. Liq. Cryst. 2012, 567, 102-109.

16. Sergent, A.; Zucchi, G.; Pansu, R. B.; Chaigneau, M.; Geffroy, B.; Tondelier, D.; Ephritikhine, M. Synthesis, characterization, morphological behaviour, and photo- and electroluminescence of highly blue-emitting fluorene-carbazolecopolymers with alkyl side-chains of different lengths. J. Mater. Chem. C. 2013, 1, 3207-3216.

17. Knaapila, M.; Dias, F. B.; Garamus, V. M.; Almásy, L.; Torkkeli, M.; Leppänen, K.; Galbrecht, F.; Preis, E.; Burrows, H. D.; Scherf, U.; Monkman, A. P. Influence of side chain length on the self-assembly of hairy-rod poly(9,9-dialkylfluorene)s in the poor solvent methylcyclohexane. Macromolecules 2007, 40, 9398-9405.

18. Cho, S. Y.; Grimsdale, A. C.; Jones, D. J.; Watkins, S. E.; Holmes, A. B. Polyfluorenes without monoalkylfluorene defects. J. Am. Chem. Soc. 2007, 129, 11910-11911.

19. Chun, H.; Manousiadis, P.; Rajbhandari, S.; Vithanage, D. A.; Faulkner, G.; Tsonev, D.; McKendry, J. J. D.; Videv, S.; Xie, E.; Gu, E.; Dawson, M. D.; Haas, H.; Turnbull, G. A.; 
Samuel, D. W.; O’Brien, D. C. Visible Light Communication Using a Blue GaN LED and Fluorescent Polymer Color Converter. IEEE Photon. Tech. Lett. 2014, 26, 20352038.

20. Chen, K. J.; Lai, Y. C.; Lin, B. C.; Lin, C. C.; Chiu, S. H.; Tu, Z. Y.; Shih, M. H.; Yu, P.; Lee, P. T.; Li, X.; Meng, H. F.; Chi, G. C.; Chen, T. M.; Kuo, H. C. Efficient hybrid white light-emitting diodes by organic-inorganic materials at different CCT from 3000K to $9000 \mathrm{~K}$. Optics Express 2015, 23, A204-A210.

21. Yu, H. J.; Park, K.; Chung, W.; Kim, J.; Chun, B. H.; Kim, S. H. White Light Emission from Blue InGaN LED with Fluorescent Conjugated Polymer Blends. Polymer J. 2009, 41, 1076-1079.

22. Santos, T. C.; Rodrigues, R. R.; Correia, S. F.; Carlos, L. D.; Ferreira, R. A.; Molina, C.; Péres, L. O. UV-converting blue-emitting polyfluorene-based organic-inorganic hybrids for solid state lighting. Polymer 2019, 174, 109-113.

23. Chang, K., Men, X., Chen, H., Liu, Z., Yin, S., Qin, W.; Yuan, Z.; Wu, C. Silicaencapsulated semiconductor polymer dots as stable phosphors for white light-emitting diodes. J. Mater.Chem.C. 2015, 3, 7281-7285.

24. Yu, H. J.; Park, K.; Chung, W.; Kim, J.; Kim, S. H. White light emission from blue InGaN LED precoated with conjugated copolymer/quantum dots as hybrid phosphor. Synt. Metals. 2009, 159, 2474-2477.

25. Jung, H.; Chung, W.; Lee, C. H.; Kim, S. H. Fabrication of white light-emitting diodes based on UV light-emitting diodes with conjugated polymers-(CdSe/ZnS) quantum dots as hybrid phosphors. J. Nanosc. Nanotechnol. 2012, 12, 5407-5411.

26. Huang, X.; Zucchi, G.; Tran, J.; Pansu, R. B.; Brosseau, A.; Geffroy, B.; Nief, F. Visibleemitting hybrid sol-gel materials comprising lanthanide ions: thin film behaviour and potential use as phosphors for solid-state lighting. N. J. Chem. 2014, 38, 5793-5800. 
27. Uthirakumar, P.; Hong, C. H.; Suh, E. K.; Lee, Y. S. Yellow light-emitting polymer bearing fluorescein dye units: Photophysical property and application as luminescence converter of a hybrid LED. Reactive \& Functional Polymers 2007, 67, 341-347.

28. Zucchi, G.; Maury, O.; Thuéry, P.; Gumy, F.; Bünzli, J. C.; Ephritikhine, M. 2,2’bipyrimidine as efficient sensitizer of the solid-state luminescence of lanthanide and uranyl ions from visible to near-infrared. Chem. Eur. J. 2009, 15, 9686-9696.

29. Zucchi, G.; Jeon, T.; Tondelier, D.; Aldakov, D.; Thuéry, P.; Ephritikhine, M.; Geffroy, B. White electroluminescence of lanthanide complexes resulting from exciplex formation. J. Mater. Chem. 2010, 20, 2114-2120.

30. Zucchi, G.; Thuéry, P.; Rivière, E.; Ephritikhine, M. Europium (II) compounds: simple synthesis of a molecular complex in water and coordination polymers with 2,2'bipyrimidine-mediated ferromagnetic interactions. Chem. Commun. 2010, 46, 9143-9145.

31. Zucchi, G.; Le Goff, X. F. Magneto-structural and photophysical investigations on a dinuclear Sm (III) complex featuring 2,2'-bipyrimidine. Inorg. Chim. Acta. 2012, 380, 354-357.

32. Akdas-Kilig, H.; Roisnel, T.; Ledoux, I,; Bozec, H. L. A new class of bipyrimidinebased octupolar chromophores: synthesis, fluorescent and quadratic nonlinear optical properties. New J. Chem. 2009, 33, 1470-1473.

33. Peng, X.; Wu, Q.; Jiang, S.; Hanif, M.; Chen, S.; Hou, H. High dielectric constant polyimide derived from 5,5'-bis[(4-amino) phenoxy]-2,2'-bipyrimidine. J. Appl. Polym. Sci. 2014, 131, 40828, 1-6.

34. D'souza, D. M.; Leigh, D. A.; Papmeyer, M.; Woltering, S. L. Woltering. A scalable synthesis of $5,5^{\prime}$-dibromo-2,2'-bipyridine and its stepwise functionalization via Stille couplings. Nat. Prot. 2012, 7, 2022-2028.

35. Dantas de Morais, T.; Chaput, F.; Boilot, J. P.; Lahlil, K.; Darracq, B.; Lévy, Y. Hole mobilities in sol-gel materials. Adv. Mater. Opt. Electron. 2000, 10, 69-79. 
36. Kanbara, T.; Kushida, T.; Saito, N.; Kuwajima, I.; Kubota, K.; Yamamoto, T. Preparation and properties of highly electron-accepting poly (pyrimidine-2,5-diyl). Chem. Lett. 1992, $21,583-586$.

37. Hu, R.; Qin, A.; Tang, B. Z. AIE polymers: Synthesis and applications. Prog. Polym. Sci. 2020, $100,1-15$.

38. Zucchi, G.; Murugesan, V.; Tondelier, D.; Aldakov, D.; Jeon, T.; Yang, F.; Thuéry, P.; Ephritikhine, M.; Geffroy, B. Solution, solid state, and film properties of a structurally characterized highly luminescent molecular europium plastic material excitable with visible light. Inorg. Chem. 2011, 50, 4851-4856.

39. Santhosh Babu, S.; Aimi, J.; Ozawa, H.; Shirahata, N.; Saeki, A.; Seki, S; Ajayaghosh, A.; Mohwald, H.; Nakanish, T. Solvent-Free Luminescent Organic Liquids. Angew. Chem. Int. Ed. 2012, 51, 3391-3395.

40. Beaupré, S.; Boudreault, P. L. T.; Leclerc, M. Solar-Energy Production and Energy-Effi cient Lighting: Photovoltaic Devices and White-Light-Emitting Diodes Using Poly(2,7-fl uorene), Poly(2,7-carbazole), and Poly(2,7-dibenzosilole) Derivatives. Adv. Mater. 2010, 22, E6-E27.

41. Li, J. J.; Wang, J. J.; Zhou, Y. N.; Luo, Z. H. Synthesis and characterization of polyfluorene-based photoelectric materials: the effect of coil segment on the spectral stability. RSC Adv. 2014, 4, 19869-19877.

42. Nakamura, T.; Sharma, D. K.; Hirata, S.; Vacha, M. Intrachain aggregates as the origin of green emission in polyfluorene studied on ensemble and single-chain level. J. Phys. Chem. C. 2018, 122, 8137-8146.

43. Kobin, B.; Behren, S.; Braun-Cula, B.; Hecht, S. Photochemical Degradation of Various Bridge-Substituted Fluorene-Based Materials. J. Phys. Chem A. 2016, 120, 5474-5480.

44. Gaal, M.; List, E. J.; Scherf, U. Excimers or emissive on-chain defects? Macromolecules 2003, 36, 4236-4237. 